\title{
Electrochemical Properties of Cellulose-nano-fiber/Reduced graphene oxide/Carbon-nano-tube Aerogel
}

\author{
Zihao $X u^{1}$, Chun $\mathrm{Wei}^{1,2, *}$, Yongyang Gong ${ }^{1,2, *}$, Jiayou $\mathrm{Hu}^{1}$, Linlin $\mathrm{Du}{ }^{1}$ \\ ${ }^{1}$ College of Materials Science and Engineering, Guilin University of Technology, Guilin 541004, P. R. \\ China \\ ${ }^{2}$ Key Laboratory of New Processing Technology for Nonferrous Metals and Materials, Ministry of \\ Education \\ *E-mail: 1986024@glut.edu.cn (C. Wei), yygong@glut.edu.cn (Y. Gong)
}

doi: $10.20964 / 2017.10 .17$

Received: 12 May 2017 / Accepted: 19 July 2017 / Published: 12 September 2017

\begin{abstract}
Using the environmentally cellulose-nano-fiber as the precursor, we prepared a CNF/RGO/MWNT aerogel electrode material via mechanical blending and freeze-drying methods. The effect of RGO/MWNT content on the performance of the aeroge electrode was studied. The structure of the material was characterized with XPS and XRD. The electrochemical performance was characterized with an electrochemical workstation. The morphology was characterized by SEM. The results show that the CNF/RGO/MWNT aerogel electrode possessed good charge and discharge properties, and the specific capacitance increased firstly and then decreased with the increase the content of RGO. The internal resistance of the electrode material decreased with the increase of MWNT content. At a $\mathrm{CNF} / \mathrm{RGO} / \mathrm{MWNT}$ ratio of 30/40/30 and current density of $1 \mathrm{~A} \cdot \mathrm{g}^{-1}$, the specific capacitance reached a maximum of $88.08 \mathrm{~F} \cdot \mathrm{g}^{-1}$. After 1000 charge-discharge cycles, the capacitance retention rate was 95.4\%, reflecting great stability. SEM results show that CNF was effectively incorporated into RGO/MWNT. The CNF/RGO/MWNT aerogel has a highly-connected three-dimensional porous network structure.
\end{abstract}

Keywords: cellulose-nano-fiber, graphene oxide, carbon-nano-tube, aerogel

\section{$\underline{\text { FULL TEXT }}$}

(C) 2017 The Authors. Published by ESG (www.electrochemsci.org). This article is an open access article distributed under the terms and conditions of the Creative Commons Attribution license (http://creativecommons.org/licenses/by/4.0/). 